\title{
Study on the Project Supervision System Based on the Principal-Agent Theory
}

\author{
Runtong Zhang, Yang Zhou, Hongnan Zhuang, Xiaomin Zhu \\ Beïing Jiaotong University (China) \\ rtzbang@bjitu.edu.cn,12120678@bjtu.edu.cn,13120650@bjtu.edu.cn,xmsbu@bjitu.edu.cn
}

Received: November 2014

Accepted: January 2015

\section{Abstract:}

Purpose: In order to solve problems in the current project management system, the paper presents the asymmetric information games existing in construction projects through information economics viewpoints.

Design/methodology/approach: The owner has private information about the project profitability and he exerts an unobservable level of effort in order to increase the feasibility of successfully completing the project in terms of meeting product specifications. The paper analyzes the principal-agent relationship between the owner and supervisor with "principalagent theory" of the game theory. In addition, the paper validates the model through two project cases.

Findings: We can conclude that the incentive contract plays an important role in reducing the moral hazard. The main contribution of this study is to examine the influence of both precontractual private information and the sensitivities between the interrelated performance measures on the design of an optimal incentive contract.

Social implications: At last, some advices are put forward to advance the project management system in China, and some external mechanism can effectively inhibit the "moral hazard" and "adverse selection" to occur. 
Originality/value: A model of principal-agent relationship between the owner and supervisor is formulated. This model takes consideration of the moral hazard, which is different from most existing researches in this field.

Keywords: project supervision, asymmetric information, principal-agent

\section{Introduction}

The project management system of China's construction market has experienced a long process of three systems. The first one is the unitary planned economy system; the second one is the binary model between owner and contractor; the third one is the currently used triangle model between owner, contractor and supervisor (Liu, 2007). The introduction of the project supervision system is designed to form the equilibrium among the construction market participants. However, there are a series of problems in the actual operation of the project supervision system, which seriously restrict the formation of the market mode (Huang, Cheng \& Tan, 2003). The development of information economics has given a good explanation for the above problems. The economics of information, which uses the asymmetrical information game theory, is an application in economics, and it is also a new development of microeconomics. The hypothesis of information asymmetry is the foundation of the existence of information economics. In the construction market, the owner and the contractor are the parties of the information asymmetry game. The introduction of project supervision system can reduce the information asymmetry, so that the game is becoming fairer. It is in consonance with the supervising principles of fairness and justice. In China, the supervision market is still in the period of development. Therefore it is urgent to use a comprehensive and fair bidding system in construction market to solve this problem.

\section{The Principal-Agent Problem}

The principal-agent problem or agency dilemma occurs when one person or entity (the "agent") is able to make decisions that impact, or on behalf of, another person or entity: the "principal". The dilemma exists because sometimes the agent is motivated to act in his own best interests rather than those of the principal. The agent-principal relationship is a useful analytic tool in political science and economics, but may also apply to other areas.

The problem arises where the two parties have different interests and asymmetric information (the agent having more information), such that the principal cannot directly ensure that the agent is always acting in its (the principal's) best interests[2], particularly when activities that are useful to the principal are costly to the agent, and where elements of what the agent does 
are costly for the principal to observe. Moral hazard and conflict of interest may arise. Indeed, the principal may be sufficiently concerned at the possibility of being exploited by the agent that he chooses not to enter into a transaction at all, when that deal would have actually been in both parties' best interests: a suboptimal outcome that lowers welfare overall. The deviation from the principal's interest by the agent is called 'agency costs (Hu, 2004).

Various mechanisms may be used to align the interests of the agent with those of the principal. In employment, employers (principal) may use piece rates/commissions, profit sharing, efficiency wages, performance measurement (including financial statements), the agent posting a bond, or the threat of termination of employment.

As a solution to the principal-agent problem, though, tipping is not perfect. In the hopes of getting a larger tip, a server, for example, may be inclined to give a customer an extra large glass of wine or a second scoop of ice cream. While these larger servings make the customer happy and increase the likelihood of the server getting a good tip, they cut into the profit margin of the restaurant. In addition, a server may dote on generous tippers while ignoring other customers, and in rare cases harangue bad tippers.

\section{The Establishment of the Principal-Agent Model}

In the engineering construction, the information asymmetry between the owners and supervisors often leads to the moral hazard problem, which means the supervision work performance will be far from the owner's intended target (Zhu, Zhou \& Wu, 2011).

This section will use the "principal-agent theory" to analyze the principal-agent relationship between the owner and the supervisor in the project supervision system. According to the different assumptions, there are two different kinds of principal-agent models between the owner and the supervisor (Qin, 2004). And then, we can get the analysis of the owner and the supervisor's choice and behavior.

\subsection{The Certain Principal-agent Model of Fixed Compensation}

There are three hypotheses, which are the preconditions of this model.

Hypothesis 1: The principal-agent relationship between the owner and supervisor is based on a kind of standard contract. The owner only chooses whether it provides the contract, but the owner can't choose to pay the remuneration or functions paid to the supervisor. 
Hypothesis 2: The supervisor's work is without uncertainty, which means that the output of the supervisor is a certain function to the degree of efforts. Therefore, the owner can master supervisor's working condition according to the results.

Hypothesis 3: The supervisor's behavior choice is discrete, only including hard work and lazy work.

In this model, firstly, the owner decides whether to receive a trust. Besides, the supervisor determines whether or not to accept the contract. Finally the supervisor chooses how to work hard after the contract. This is a three-stage game, which can be described by a game tree.

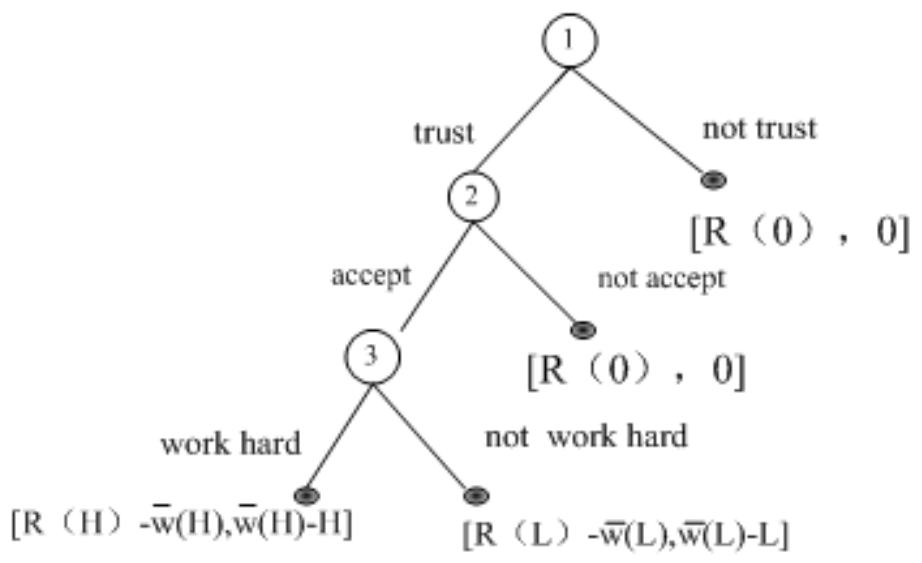

Figure 1. Principal-agent game tree

Now we analyze the game between them under the assumptions closed to the actual situation. In this game, the two parties know clearly about the profits about the two sides and they can observe the choices of the opposite side. Therefore, the game is a complete and perfect information dynamic game, which can be analyzed by the backward induction.

Firstly, analysis of the supervisor's level of efforts plays an important role in the third stage. If the supervisor tries to work hard, the owner can get a high output $\mathrm{R}(\mathrm{H})$ and he must pay for the supervisor a high wage $\varpi(H)$; the supervisor gets a high $\varpi(H)$, but he has a high negative utility (cost) $-H$. Ultimately, the gains of the owner is $R(H)-\varpi(H)$, and the supervisor's profit is $\varpi(H)-H$. If the supervisor chooses not to work hard, so the owner gets a low output $R(L)$; the supervisor gains a low wage $\varpi(L)$, and has a lower negative utility $-L$. In the end, the benefit of the both sides respectively is $R(L)-\varpi(H)$ and $\varpi(L)-L$. According to the principle of rational game, if:

$$
R(H)-H>\varpi(L)-L
$$


At this time, the supervisor will choose to work hard. The inequality (1) is an incentive compatibility constraint (IC) of the hardworking supervisor. The hardworking supervisor to be paid can get the basic pay or more than the lazy ones. At the same time, the wage of the struggling must can compensate for a greater negative effect than the lazy ones. As a consequence, the supervisor could choose to work hard automatically. If the constraint conditions cannot be met, the supervisor must choose not to take efforts.

Secondly, it is essential to judge whether the supervisor accepts the commission. For the third stage the supervisor can choose whether to work hard, corresponding to different benefits. As the rational game party, in both cases, the conditions for the supervisor choosing to accept the contract are: $\varpi(H)-H>0$ (work hard); $\varpi(L)-L>0$ (not work hard).

The two inequalities are the constraint conditions which can decide the supervisor's choice. The economic meaning is: the supervisor's profit from the contract can't get less than the maximum of not accepting the contract. This is the basic condition for the supervisor accepting the commission.

Finally, the choice of the first stage needs a detailed explanation. $R(0)$ stands for the owner's profit when the owner doesn't entrust a supervisor. If the supervisor chooses to refuse in the second stage, the owner's choice is without meaning. If the supervisor chooses to accept the commission in the second stage, the owner makes the decision according to the supervisor's choice in the third stage. Only when the supervisor's benefits are positive, can the owner choose to entrust.

By summarizing the two game parties' choices, we can get the sub-game perfect Nash equilibrium. This model is a complete process of signing the contract. As rational parties, the owner must get more profit by the commission. The supervisor demands he should get a greater benefit than (or at least equal to) the maximum income when not accepting the contract. While working hard makes greater benefits, the supervisor will naturally choose to make efforts.

\subsection{The Uncertain Principal-Agent Model of Selective Compensation}

The above model is under some additional assumptions. The supervisor's work is certain and observable, which obviously is a simplification of the reality. Now we analyze the game between them under the assumptions closed to the actual situation.

Hypothesis 1: The supervisor's work is uncertain, which means his output is not only determined by his own efforts, but also by the outside control of the objective conditions.

Hypothesis 2: The supervisor can choose the reward function, that is, the pay system. 
Hypothesis 3: The supervisor's level of efforts is a continuous variable, assuming e is a one-dimensional continuous variable.

Hypothesis 4: The owner is risk neutral; however, the supervisor is the type of riskaverse.

In addition, the supervisor has a positive opportunity cost when he doesn't accept the commission. Then we analyze the principal-agent model under the above assumptions.

Firstly, assume that the supervisor's output function and the level of effort is linear relationship: $\Pi=e+\theta . \theta$ obeys the normal distribution, where $\mu=0, \operatorname{Var}=\sigma^{2}$, standing for the exogenous uncertain variable. By the formulas: $E \pi=E(e+\theta)=e, \operatorname{Var}(\pi)=\sigma^{2}$, we can conclude that the effort of supervisor decides the $\mu$, not affecting the Var. Suppose the contract between the two parties using a linear: $s(\pi)=\alpha+\beta \pi$, where $\alpha$ is the fixed income of the supervisor (nothing to do with the $\pi$ ), and $\beta$ is the project share of the output. $\beta=0$ means that supervisor doesn't take risk. $\beta=1$ means that the supervisor bears all the risk. Because the owners are risk neutral, given $s(\pi)=\alpha+\beta \pi$, the owners' expected utility equals to expected income:

$$
\operatorname{Ev}(\pi-S(\pi))=E(\pi-\alpha-\beta \pi)=-\alpha+E(1-\beta) \pi=-\alpha+(1-\beta)
$$

Assume the utility function of the supervisor is with characteristics of risk-adverse.

That is $\mu=-\mathrm{e}^{\rho \sigma}$, where $\rho$ is the absolute measure of risk aversion, $\varpi$ is the real international monetary income. Assume the supervisor's cost: $c(e)=\frac{1}{2} b e^{2}$, where b represents the cost factor. With the same effort, the larger $b$ is assigned, the greater negative is brought. The supervisor's actual income is:

$$
\varpi=s(\pi)-c(e)=\alpha+\beta(e+\theta)-\frac{1}{2} b e^{2}
$$

Because the supervisor is risk-averse, the certainly equivalent income equals to the mean income minus the random cost of risk. Therefore, uncertainly equivalent income:

$$
E \varpi-\frac{1}{2} \rho \beta^{2} \sigma^{2}=\alpha+\beta e-\frac{1}{2} \rho \beta^{2} \sigma^{2}-\frac{1}{2} b e^{2}
$$


$\mathrm{E} \varpi$ is the supervisor's expected income. $\frac{1}{2} \rho \beta^{2} \sigma^{2}$ is the risk costs of the supervisor. When $\beta=0$, the supervisor's cost of risk is 0 , which means the supervisor doesn't take any risks at this time. The supervisor's largest expected utility function is equivalent to the certainty equivalent income, that is:

$$
\mathrm{E} \mu=\alpha+\beta \mathrm{e}-\frac{1}{2} \rho \beta^{2} \sigma^{2}-\frac{1}{2} b \mathrm{e}^{2}
$$

Where $\varpi$ stands for the supervisor's retained income levels. Therefore, if the supervisor's certainly equivalent income is less than $\varpi$, the supervisor will not accept the contract. As a consequence, the participation constraint of the supervisor is as follows:

$$
\mathrm{E} \mu=\alpha+\beta e-\frac{1}{2} \rho \beta^{2} \sigma^{2}-\frac{1}{2} b e^{2} \varpi
$$

On the incentive constraint (IC), we can carry on the analysis of two cases:

- The owners can observe the effort level of the supervisor. Because the owner can observe the effort level e, then the incentive constraint does not work. Any level of e can be achieved by meeting the mandatory contract. Therefore, the owner's problem is how to determine $\alpha, \beta$, e to achieve the maximum benefit.

The mathematical model of optimization is as follows:

$$
\begin{gathered}
\max _{\alpha, \beta, e}=-\alpha+(1-\beta) e \\
\text { s.t. } \alpha+\beta e-\frac{1}{2} \rho \beta^{2} \sigma^{2}-\frac{1}{2} b e^{2} \varpi
\end{gathered}
$$

In the best case, the equation of IR constraint is true, because the owner does not need to pay more for the supervisor. We can use the constraints to obtain by the deformation of the equation, namely:

$$
-\alpha=\beta e-\frac{1}{2} \rho \beta^{2} \sigma^{2}-\frac{1}{2} b e^{2}-\varpi
$$

Take $-\alpha$ into the objective function, getting the most objective optimization function:

$$
\max _{\alpha, \beta, e}\left(e-\frac{1}{2} \rho \beta^{2} \sigma^{2}-\frac{b}{2} e^{2}-\omega\right)
$$

Derivative of the objective function, the optimal first-order conditions were: $e^{*}=\frac{1}{b}$; $\beta^{*}=0$. 
Take the results into the IR constraint equation (7):

$$
\alpha^{*}=\bar{\omega}+\frac{b}{2}\left(e^{*}\right)^{2}=\bar{\omega}+\frac{1}{2 b}
$$

The economic analysis of the solution: $\beta^{*}=0$, the supervisor does not take any risk, and the income has nothing to do with the output; $\alpha^{*}=\omega+\frac{1}{2 b}$, that the fixed income that the owner pays to the supervisor equals to the supervisor's retained income plus the cost of effort; $e^{*}=\frac{1}{b}$ achieving an optimal level, ie $1=$ be. When the owner observes the supervisor's choice of e $<\frac{1}{b}$, he will pay for the supervisor $\alpha \varpi<\alpha^{*}$, so the supervisor will certainly choose $e=\frac{1}{b}$.

- The supervisor's effort level e can't be observed. The supervisor will choose to maximize his certainty equivalent income. After derivation calculus to equation (4), we can get: $e=\frac{\beta}{b}$.

At this point the incentive constraint for the supervisor is $e=\frac{\beta}{b}$. When the supervisor does not take any risk (for a given $\beta=0$ ), $e=\frac{\beta}{b} \Rightarrow e=0$, the supervisor will choose $e=$ 0 instead of $e=\frac{1}{b}$. The problem of the owner is how to determine $\alpha, \beta$ to achieve the maximization. The mathematical model of optimization is as follows:

$$
\begin{gathered}
\max _{\alpha, \beta, e}=-\alpha+(1-\beta) e \\
\text { s.t }\left\{\begin{array}{l}
(\text { IR }) \alpha+\beta e-\frac{1}{2} \rho \beta^{2} \sigma^{2}-\frac{1}{2} b e^{2} \geq \omega \\
\text { (IC) } e=\frac{\beta}{b}
\end{array}\right.
\end{gathered}
$$

Taking constraint (IR) and incentive constraints (IC) into the objective function, then we can obtain the following objective function:

$$
\max _{\beta}\left(\frac{\beta}{b}-\frac{1}{2} \rho \beta^{2} \sigma^{2}-\frac{b}{2}\left(\frac{\beta}{b}\right)^{2}-\omega\right)
$$

Get a first-order derivative:

$$
\frac{1}{b}-\rho \beta \sigma^{2}-\frac{\beta}{b}=0
$$


That is

$$
\beta=\frac{1}{1+b \rho \sigma^{2}}>0
$$

This solution means that the supervisor must take some risks, and $\beta$ is a decreasing function about $\rho, \sigma^{2}$ and $b$.

From the perspective of incentive, when there is no information asymmetry, the greater $\mathrm{b}$ is, the smaller e (the optimal $\mathrm{e}^{*}=\frac{1}{\mathrm{~b}}$ ) is. From the perspective of risk-sharing, the greater $b$ is, the bigger $\beta\left(e=\frac{\beta}{b}\right)$ is. The owner prefers a lower risk of cost savings. If the level of effort can be observed when $\beta=0$, the optimal effort level of $e=\frac{1}{b}$; on the other side, when $\beta>0$, the supervisor can automatically select the optimal effort level:

$$
\mathrm{e}=\frac{\beta}{\mathrm{b}}=\frac{1}{\mathrm{~b}\left(1+\mathrm{b} \rho \sigma^{2}\right)}<\frac{1}{\mathrm{~b}}
$$

Analysis:

- The optimal level of effort under the asymmetric information strictly less than the level of effort under the symmetric information. So when the owners can't observe the measured $e$, the supervisor will choose $e<e^{*}$ to improve their welfare. Because the level of output not only relates to the level of effort with the supervisor, but also by the impact of exogenous variables $\theta$. Attributed to adverse exogenous effects (such as some non-objective control conditions, including the natural conditions), so the supervisor can avoid accusations of the owners. This is the so-called "moral hazard" problem.

- The owner can't observe the supervisor's effort level e, the supervisor should bear risk than the symmetric information cases.

Conclusion: When the owner can observe the effort level e of the supervisor, both sides have the symmetric information. Both Pareto optimal risk-sharing and Pareto optimal level of effort can be achieved. The Pareto optimal contract: the supervisor doesn't take any risk, and the owner pay fixed income $\alpha^{*}=\omega+\frac{1}{2 b}$ (the supervisor's retained income plus the cost of effort) to the supervisor. Therefore, the optimal level of effort is $e^{*}=\frac{1}{b}$. 
When the owner can't observe the effort level e of the supervisor, that is, there is asymmetric information. Both Pareto optimal and Pareto optimal risk-sharing can 't be achieved, then the optimal contract is: to design a given incentive $\left(\beta^{*}>0\right)$, the supervisor takes some risks, whose optimal level of effort less than that under the symmetric information. The owner selects the expected conducts through the selection and designed incentives to maximize their expected income.

\section{Project Case}

\subsection{Case One}

The owner of a construction prepares to seek a supervision unit. There are three units have the cooperation intention, and the owner can observe the effort level of the supervision unit. The first supervision unit $A$ requires the owner to pay the minimum wage RMB 2,000 to the supervisors. The effort cost factor $b$ is 0.0002 . The second supervision unit $B$ requires the owner to pay the minimum wage RMB 2,300 to the supervisors. The effort cost factor $b$ is 0.0003 . The third supervision unit $C$ requires the owner to pay the minimum wage RMB 2,500 to the supervisors. The effort cost factor $b$ is 0.0005 . According to the optimal linear contract under the condition that the supervisor's effort level e can be observed, the results are shown in the table. From the calculated results in the Table 1, the owner should choose the third supervisor unit $\mathrm{C}$.

\begin{tabular}{|c|r|r|r|r|r|}
\hline supervisor & //RMB & b & //RMB & //RMB & \multicolumn{1}{|c|}{$/ /$ RMB } \\
\hline A & 2,000 & 0.0002 & 5,000 & 4,500 & 500 \\
\hline B & 2,300 & 0.0003 & $3,333.3$ & $3,966.7$ & -633.4 \\
\hline C & 2,500 & 0.0001 & 10,000 & 7,500 & 2,500 \\
\hline
\end{tabular}

Table 1 . The calculated results of game analysis between the owner and the supervisor

\subsection{Case Two}

One project owner intends to sign a principal-agent contract with a supervisor. The owner can't observe the supervisor's effort level. The cost factor is $b=0.0001$; the absolute measure of risk aversion $\rho=0.1$; the minimum wage is $\sigma=2,000$; the exogenous uncertain variable $\theta \sim \mathrm{N}(0.3002)$. 
According the formulas, we can get:

$$
\begin{aligned}
& \beta=\frac{1}{1+b \rho \sigma^{2}}=\frac{1}{1+0.0001 \times 0.1 \times 90,000}=0.526 \\
& e=\frac{\beta}{b}=\frac{0.526}{0.0001}=5,263.158 \\
& \alpha=\omega+\frac{1}{2} b e^{2}+\frac{1}{2} \rho \beta^{2} \sigma^{2}-\beta e=2,000+1,385.042+\frac{1}{2} \times 0.1 \times 0.526^{2} \times 90,000-0.526 \times 5,263.158 \\
& =1,861.496 \\
& s(\pi)=\alpha+\beta \pi=\alpha+\beta(e+\theta)=1,861.496+0.526 \times 5,263.158=4,630
\end{aligned}
$$

At last, we can get the result: $s(\pi)=4,630 \mathrm{RMB}$, that is, if the owner signs the above contract with the supervisor, their profit will achieve balance at the same time.

\section{The Impact of the Construction Supervision System}

In the economic market, the rights and obligations among economic actors are expressed through contracts. Once the contract relationship is established, it is difficult to observe the conduct of the parties, which may result in moral hazard. The principal-agent model is the basic framework to solve this problem. In the transaction process, the party with information advantage is called the agent, while the other side is called the principal. The assumption behind the definition is that the private information will affect the interests of the insiders (Zheng, 2002). In the construction market, the relationship between the owner and the supervisor is a typical principal-agent model.

\subsection{The Basic Problem}

The principal-agent relationship between the owner and the supervisor is the foundation of the existence of the construction supervision system. The meaning of the construction supervision is: the supervisor accepts the commission of the owner, and the supervisor should stands for the owner to conduct the micro-supervision and management according to state-approved construction, project construction documents, the construction of laws, regulations and supervisory construction. From the meaning of the term, since the owner commissions the supervisor, it would depend on the supervisor to implement the construction supervision and management. The owner of the provisions implements their own rights and obligations within the scope of supervision. The owner should not be beyond the supervision of the contract rights. However, in the actual construction, the problem lies in the fact that the owner often interferes with the supervising supervisor of the construction supervision and management. 
The destruction of the principal-agent relationship between the owners and the supervisor is closely related to the potential moral hazard. In the actual construction market, because of the absence of better incentive system, China's supervision is still in the early stages of development. The credit of supervision industry is low, and some supervisors are of low quality. Therefore, the owner often breaks the principal-agent relationship, in order to avoid potential moral hazard. This destruction between the owner and the supervisor leads to a direct consequence of more asymmetric information, intensifying the fraud of the construction market, increasing the costs of society.

In the principal-agent relationship between owners and supervisors, there are two stages of information asymmetry. As the owner has no knowledge of the ability of supervisors, knowledge and reputation and other private information before signing the contract, owners may lead to lower prices over the ability of supervisors out of a competitive market, so that some low-level supervisors stay. Then the "adverse selection" arises. After signing the contract, when the supervisors' behavior can't be observed by owners, the information asymmetry arises, and leads to "moral hazard". Through the above principal-agent game analysis between owners and supervisors, we can see that under asymmetric information, inhibition of "moral hazard" and "adverse selection" by the internal mechanism is designed to achieve reasonable contract supervision. At the same time some external mechanism can effectively inhibit the "moral hazard" and "adverse selection" to occur. China has adopted a supervision system for more than ten years, and the supervision system in the healthy development of reform and construction industry has played an important role. However, the low commission fees, inadequate supervision and other issues are increasingly prominent, which is a serious impact on the further deepening of supervision system. Through the relationship of the principal-agent game analysis between owners and supervisors, we can reduce the "moral hazard" and "adverse selection" by well-designed contract, while achieving the interests of owners and supervisors to maximize the long-term interests, so as to achieve "win-win" is a matter of concern.

We have studied optimal incentive contracts offered to a research and development (R\&D) manager, who can propose an innovative project and is in charge of conducting this project. The solution to our optimal contracting model shows that incentives on the basis of the firm's market value are stronger for more profitable than for less profitable projects, and incentives on the basis of efficiency objectives are stronger for less profitable than for more profitable projects. The reason for the latter counter intuitive result is that strong incentives on the basis of the firm's market value place too much risk on the project manager, in particular, for executing his routine job. These strong incentives are softened by reducing incentives for efficiency objectives that directly affect the effort in the routine job. 


\subsection{The Current Situation}

The introduction of the construction supervision system effectively reduces the asymmetric information in project construction. However, the degree of the asymmetric information is related to the ability providing high-quality and high-tech services. After ten years of development, the project management industry in China has made great progress in significant quantities, but it varies greatly in quality. The qualified supervision is less than $10 \%$. The reasons for a lower level of supervision of the industry are various, such as the community supervision system is not completely. It's also related to the supervision of industry and personnel structure, training and personnel mechanisms. In our present supervision of employees in the industry, vast majority of supervisors are from the construction, design department. This part of the staff has a good supervisory; however, they are not proficient in the economy, laws, regulations and policies for the economy market of today. Therefore, developing a number of high-quality supervisory, supervision as soon as possible is urgency.

However, both the social and the current higher education don't have the training on the supervision industry. Even if the supervisory unit doesn't have a long-term plan and a complete incentive system, people don't realize that the lack of talent is the bottleneck to restrict its development. And a supervision of the construction industry of low quality can't meet the reduction of asymmetric information to the market requirements. As China enters the WTO, the international market and domestic market opens, as a result, supervision is facing severe challenges, which also brings opportunities. It is more essential to train a high-quality supervision team.

\section{The Solution of the Asymmetric Information}

In summary, the supervision market in China has been improved to a certain extent, but there are still some problems to solve. In face of the structure of the open market today, it is an urgent matter for us to strengthen. It is a realistic problem to make the construction industry in China occupying a place in the international market. The asymmetric information in the construction industry is common. It is a question for each practitioner and theoretical study to focus on, which includes how to regulate the behavior of participants and how to eliminate the asymmetric information. It requires the building practitioners and the market managers to understand the importance of the asymmetric information in-depth. The parties need to be aware of the significance of the elimination of asymmetric information. As for the serious trouble currently in the construction project management, the solutions should be proposed timely. 


\subsection{For the Owner}

- Strengthen the owners' monitoring mechanism. From the analysis of the boundary function, we can see that the larger the penalties are, the greater the level of its regulatory efforts is. So the owner can have a greater space of supervision. As a consequence, it is better to promote the careful supervision of the commissioner of party choice behavior. Therefore, in the actual operation of the construction, owners should strengthen supervision and management, and establish a good transport mechanism, effectively suppressing the third-party misconduct, to ensure the successful completion of the project.

- Achieve project management are instead of supervision system. Employ professional project Management Company to manage the entire project. Create new project management model. Use the consecutive payments incentive mode in stage in the project management, so that the agent can understand the existence of the incentive, prompting them to work hard. There are many factors about the supervisor's performance rewards. Firstly consider the quality of the supervisor, which decides the ability level, the absolute risk aversion degree and the effort cost. The stronger of the supervisor's ability is, the greater of the ability with risks is, and the more adventurous of personality characteristics. The owner of the project chooses a supervisor which should be suited to the characteristics of the project on quality as the premise of the incentive mechanism playing its proper efficiency. Under the condition of asymmetric information, the Pareto optimal linear contract can be achieved. Because of the owner is a risk neutral party, the agent should be aware of the risk aversion, Pareto risk sharing requests the supervisor not assuming any risk, and the owner don't need to make any incentive agent. Under the condition of asymmetric information, the performance reward that the supervisor gets should reflect the changes in the external environment condition. The owner's performance reward is scheduled generally according to the project performance, but the project performance not only completely depends on the effort level, but also the result of the joint of the external environment factors. When the risk increases, the owner should reduce the risk level. When the supervisor's risk reduces, the owner should increase the affordable risk of the supervisor, to motivate the agent's enthusiasm. Therefore, when making supervisor's performance rewards should exclude more external factors as much as possible. 


\subsection{For the Supervisor}

- Strengthen the internal construction of the supervision and establish a scientific and effective incentive system, such as the bonus incentives about the claimed loss and the construction process associated with quality. Internal mechanism is through rational design agent contract to develop an incentive mechanism, so that the supervisors' target will close to the owners'. Taking this measure can alleviate supervisors to take opportunistic behaviors and make the dynamic adverse selection, so that moral hazard and adverse selection can be suppressed. But whether the internal mechanism can play the expected role depends on owners' choice of supervisors, monitoring and evaluation of right or wrong, that is, it depends on the correctness of the information obtained. If owners are in order to provide high effectiveness of the operation of this mechanism, it needs the appropriate measures and cost, so that they can get the information to "select the appropriate project division "and" make the supervisor perform accurately". Therefore, the internal machine system only can reduce the efficiency of the nonagency relationship to a certain extent, but its validity is subject to the information costs and the limitation of the imperfect information. Taking the appropriate incentives to reduce the probability of moral hazard issue can reduce the illegal construction practices. Owners can sign a contract with the construction side, to meet the quality requirements of the premise in the case of early completion, giving a certain percentage reward, which are not more than the additional revenue of the illegal construction obtained. Thus, it not only can reduce the construction side's cheating space, and improve the enthusiasm of the construction to choose the normal building, also promoting the project to put into use in advance, as soon as possible to recover the investment.

- To solve the "adverse selection" and "moral hazard" in asymmetric information environment, reputation effects have a valid role. When the game only performs once or a limited time (for supervisors only exist in the market for a short-term), supervisors only care about each stage of the current income. However, if the game is infinitely repeated (the supervisor on the market for a long term), any short-term opportunistic behavior of the proceeds are negligible. 


\subsection{For the Contractor}

Show great strength to increase the punishment to illegal construction parties. Increasing the punishment can enhance the supervisor to take the work seriously and make up the mistakes that the asymmetric information has made. As a result, the risk of the moral hazard will be decreased to a great extent. The solution of the game elements of the relationship between variables and analysis increases the punishment, which can reduce cheating effectively. Many construction sites that are in order to achieve maximum self-interest, with this solution, the probability of the occurrence of moral hazard will be decreased. Although the punishment is too large to some extent can contain illegal act of construction parties, but may also reduce their construction initiative. The determination of punishment not only plays a limited role in illegal construction of the construction sides. And the actual situation should be based on the relationship between punishment and enthusiasm.

\subsection{For other Sides}

- Strengthen our building laws and regulations and speed up the construction of the standardization process of building market. Improve the existing supervision system, and establish the self-regulatory mechanism of this industry, forming a fair market, having honest ethics and values. Industry associations should make a series of information disclosure, clear and workable agreement to improve the transparency of information, to provide a platform for healthy and orderly for the supervisors. Meanwhile, the supervisor should take reasonable incentives, improving the supervision of supervision for serious acts of favorable space to a certain extent, increasing their motivation and effectiveness.

- Strengthen the education of the perpetrator in the construction market. Ensure they are aware of information asymmetry prevalent in the construction industry and the construction supervision system in addressing the role of asymmetric information.

- External mechanism is the introduction of competition between supervisors. Sound and effective competition in the market plays a self-restraint, self-monitoring role for supervisors, and has a memory function to the accumulation of the results of their actions. Reputation can be accurately reflected by the market. For reputation considerations, supervisors will make a commitment, and always tend to choose to maximize the effectiveness of the actions of owners, to get the market's trust in order to better foothold in the market. 


\subsection{Brief Summary}

The supervisor will have enthusiasm to build a good reputation to achieve greater benefits for long term. It is urgent to establish a sound and effective and competitive supervision market in China. When reputation is no longer a moral issue, but a system, the results will improve the game balance.

\section{Conclusion}

Through the above principal-agent game analysis between owners and supervisors, we can see that under asymmetric information, inhibition of "moral hazard" and "adverse selection" by the internal mechanism is designed to achieve reasonable contract supervision. At the same time some external mechanism can effectively inhibit the "moral hazard" and "adverse selection" to occur. Through two project cases, we validate the model successfully. The solution to our optimal contracting model shows that incentives on the basis of the firm's market value are stronger for more profitable than for less profitable projects, and incentives on the basis of efficiency objectives are stronger for less profitable than for more profitable projects.

\section{Acknowledgments}

This work is partially supported by a major program of the National Social Science Fund of China (Grant No. 13\&ZD026), a Specialized Research Fund for the Doctoral Program of Higher Education (Grant No. 20120009110009).

\section{References}

Hu, R. (2004). The Discussion of Information Economics to Engineering Supervision Institution. Hongshui River, (23), 97-100.

Huang, B.X., Cheng, Z.H., \& Tan, D.M. (2003). The Explanation of Information Economics to Engineering Supervision Institution. Architecture and Construction, (7), 42-45.

Liu, Y.M. (2007). Study on Project Management System through Information Economics Viewpoint. Science \& Technology Information, (19), 159-160.

Qin, X. (2004). Game Analysis of Principal-agent Relationship under the Supervisoring Supervision Institution. Soft Science of China, 04, 142-46. 
Zhu, L.M., Zhou, J., \& Wu, X.L. (2011). The Incentive Supervise Model of Project Supervision

Based on Principle-agent Theory. Operations Research and Management Science, 20(3), 176-179.

Journal of Industrial Engineering and Management, 2015 (www.jiem.org)

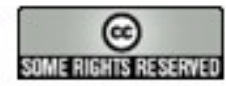

Article's contents are provided on a Attribution-Non Commercial 3.0 Creative commons license. Readers are allowed to copy, distribute and communicate article's contents, provided the author's and Journal of Industrial Engineering and Management's names are included. It must not be used for commercial purposes. To see the complete license contents, please visit http://creativecommons.org/licenses/by-nc/3.0/. 